Matthieu Glachant \& Yann Ménière

Working Paper 2010-14

Cerna, Centre d'économie industrielle MINES ParisTech

60, boulevard Saint Michel

75272 Paris Cedex 06 - France

Tél. : 33 (1) 40519000

July 2010 


\title{
Technology Diffusion with Learning Spillovers: Patent versus Free Access
}

\author{
Matthieu Glachant, Yann Ménière ${ }^{\dagger}$
}

July 29, 2010

\begin{abstract}
The paper analyzes the interplay between technology diffusion and patent law. We develop a dynamic model where initial adoptions generate learning spillovers that reduce the cost of subsequent adoptions. In this setting, we contrast technology diffusion paths under competitive supply, subsidized adoption and patent protection. Competitive supply entails various coordination failures that cannot be fully fixed through a public subsidy. We show that a patent holder can internalize externalities more efficiently, insofar as patent protection is fully effective. By contrast, fully competitive supply may be more efficient when patent enforcement is imperfect.
\end{abstract}

Keywords : Technology diffusion, intellectual property rights, price discrimination, learning spillovers

JEL code: O33, O34

\footnotetext{
*Mines ParisTech, Cerna, France, glachant@mines-paristech.fr

${ }^{\dagger}$ Mines ParisTech, Cerna, meniere@mines-paristech.fr
} 


\section{Introduction}

This paper explores the interplay between the patent system and technology diffusion. Economists view patent law primarily as a tradeoff between more innovation and less diffusion. Granting an exclusive right restricts access to technology as innovator can charge the monopoly price, but the monopoly profit induces more efforts ex ante.

This view neglects a crucial characteristic of technological diffusion: the adoption of technologies generally entails learning externalities. Learning-bydoing generates cost reductions which spread through labor mobility or other channels. Early adoptions may also induce demonstration effects which facilitate further adoptions. They can reduce the uncertainties surrounding the benefits of adoption, thereby facilitating the cost-benefit analysis of subsequent adopters. The empirical literature suggests that such cross-firm learning spillovers are substantial (see for instance Thornton and Thompson, 2001; Irwin and Klenow, 1994; Gruber, 1998).

Whereas it is well known that a competitive industry does not internalize external benefits, there is reason to suppose that a monopolist can partly do so. As regards specifically innovation markets, a monopolist holding a patent can discriminate prices. It can offer rebates to the early adopters who generate externalities while charging the followers higher prices. To sum up, the impact of Intellectual Property Rights (IPR) may not be as straightforward as traditionally thought. In this paper, we develop a model to shed light on these issues.

Apart from its theoretical motivation - the role of IPR in the internalization of learning spillovers -, our analysis directly echoes with a recurrent policy debate on the international diffusion of technology between industrialized and developing countries. The latter often fear that strict IPR might restrict the dif- 
fusion in their economies of technologies developed abroad. The former however insist on the fact that IPR are necessary for marketing new technologies ${ }^{1}$. The debate started vigorously during the negotiations of the Agreement on Trade Related Aspects of Intellectual Property Rights (TRIPS) which sets down minimum standards for IPR. Although the TRIPS agreement was adopted in 1994, discussion are on-going, notably on difficult implementation issues such as the conditions under which free access to a patented technology is authorized - or compulsory licensing is possible. Our model seeks to provide useful insights for this debate.

We consider a set of $n$ firms which initially operate with an old technology. They can adopt a better technology simultaneously or sequentially. Adoption entails a fixed cost. A key assumption in the model is that this cost starts decreasing once the technology has been adopted by a first firm. It allows us to capture the collective learning-by-doing process whereby later adopters benefit from the experience of former ones through various channels (e.g. direct observation, labor market).

We compare different situations. The first is a laisser-faire scenario in which the technology is provided competitively. We show that learning spillovers generate two types of inefficiency. The first is the traditional under-provision problem. When spillovers are substantial, the first adoption may not be profitable and may never occur, although technology diffusion would be socially optimal. The second is a coordination problem. All firms would prefer to follow in order to enjoy a reduced adoption cost. But following requires that one firm takes the lead. As a result, the first adoption is delayed, althuogh it is (privately and socially) profitable. Significantly, the wider the gap between the leader's and the followers' payoffs, the longer the delay will be.

\footnotetext{
${ }^{1}$ Empirical results suggest that the impacts of IPR strictness on diffusion vary widely across host countries (Maskus, 2000; Smith, 2001).
} 
Surprisingly, we show that the canonical solution to this problem - a Pigovian subsidy to the leader equal to the total external benefits - fails to implement the social optimum in certain circumstances. In particular, the subsidy is suboptimal when learning spillovers are low. The reason is that the leader's payoff, which includes a low subsidy, remains below that of the followers. As a result the coordination problem subsists.

We then consider a second scenario in which the technology is patented and supplied by a single provider. In contrast with the subsidy, the patent holder always reaches the first-best outcome by discriminating between adopters to mitigate the inefficiencies generated by learning spillovers. The intuition is that the patent holder can subsidize the first adoption of weakly profitable technologies that would not otherwise be diffused. Moreover, inter-temporal price discrimination eliminates the coordination problem as the patent owner is able to reap the followers' adoption surplus.

Finally, we extend the model to analyze imperfect enforcement of IPR which concerns many developing countries nowadays. We show that imperfect enforcement damages social welfare. This can even lead to worse outcomes than the laissez-faire scenario when enforcement is particularly weak.

The paper is organized as follows. Sections 2 and 3 present respectively a motivating example and a review of the literature. Section 4 presents the model, and displays the socially optimal technology diffusion path. Section 5 explores the diffusion path when access to the technology is free. We characterize the equilibrium diffusion path, and highlight inefficiencies due to strategic adoption behaviors. In Section 6 we extend the analysis to the case of exclusive proprietary technologies. In Section 7 we derive policy lessons and we conclude in Section 8 . 


\section{An example}

The introduction of a new type of blended cement in the Indonesian market in 2004 provides an interesting illustration of the spillovers generated by technology adoption and the strategic problems they can induce. The production of the traditional so-called Ordinary Portland Cement (OPC) is highly energy intensive. Against this background, producing blended cement is a way to reduce energy consumption by replacing part of the clinker input with additive materials such as limestone and pozzolan.

In 2004 the OPC was the only cement sold in the Indonesian market when the second-largest Indonesian cement producer, the Indocement group, decided to import a blended cement technology developed by European companies in the $1990 \mathrm{~s}^{2}$. For this purpose, Indocement had to overcome a technological barrier that was lifted for subsequent adopters: as some of the components of the European blended cement were unavailable in Indonesia, Indocement had to invest in research to create an altered blended cement using local inputs (such as coal fly and volcanic ash).

A second barrier was potential consumer aversion to this particular type of cement. Indocement's was not the first attempt to introduce blended cement in Indonesia. In the early 1980 's, a first endeavour failed due to product quality problems. After that the technology improved substancially but, despite its increasing success abroad, re-introducing blended cement in the market was considered as a risky market innovation.

Indocement finally launched the new product with great commercial success: the new cement accounted for roughly $88 \%$ of Indocement's total domestic cement sales in 2007 (http://www.indocement.co.id/new/marketing.asp). This

\footnotetext{
${ }^{2}$ Detailed information on this project is available on the United Nations Framework Convention on Climate Change website as it was registered as a Clean Development Mechanism project under the Kyoto Protocol (see http://cdm.unfccc.int/Projects/DB/DNVCUK1156111801.9)
} 
commercial success has paved the way for other local firms that have recently followed Indocement.

This case affords two insights which are central in the model below. First early adoptions generate learning spillovers for subsequent adopters: Indocement has tested whether customers were still reluctant to use blended cement. Second, this creates a second mover advantage which can generate adoption delays. It is very likely that blended cement would have been introduced earlier in the market in the absence of these informational spillovers.

\section{Literature review}

A strand of literature in international economics explores how North-South technology transfers are affected by stronger intellectual property rights in the South (Lai, 1998; Glass \& Saggi, 2002; Lai \& Qiu, 2003; Glass, 2004). Adopting a macroeconomic approach, these papers mainly focus on the Northern innovators' incentives to undertake FDI in Southern countries under the threat of imitation. Our approach is different, and complements this literature. We focus indeed on the timing of introduction and local diffusion of a Northern technology within a Southern country. Since we want to characterize the impact of patent law on the strategic adoption behaviours of Southern firms, we follow an industrial organization approach.

The theoretical literature on technology diffusion in industrial organization is well-developed with two seminal contributions by Reinganum (1981) and Fudenberg and Tirole (1985). Hoppe (2002) gives a good overview.

This is essentially a positive literature which seeks to explain why the diffusion of new technologies is gradual. One common feature is competition between

potential adopters. Two effects are typically present: the competitive advantage of adopting a technology early-the preemption effect-, and better information 
on the technology value or reduced adoption costs when adopting late.

Unlike us, these authors do not assume that early adoptions generate externalities for late adopters as information flows or the decline of adoption costs are influenced not by previous adoptions, but by time. They analyse strategic effects in the product market ${ }^{3}$ whereas we do not.

In this regard, we are closer to Mariotti (1992) who also assumes a competitive downstream market and highlights coordination failures which induce adoption delays. Inefficient delays also appear in a paper by Bolton and Farell (1990) which deals with the timing of entry into a new market. But the reason for inefficiency is different from the one given in our paper. Due to private information and lack of coordination, potential entrants fear "entry mistakes" if they would enter simultaneously into a natural monopoly market.

None of these papers examines the role of IPR. The exact opposite is true of the rich literature on patent licensing which studies the pricing behavior of patent holders (see for instance Kamien, 1992; Erutku and Richelle, 2007). However, it does not consider the role of external learning benefits which lie at the core of our paper.

David and Olsen (1992) and Katz and Shapiro (1987) are closest to our work. Like us, David and Olsen (1992) study the diffusion of a cost-decreasing technology in an industry characterized by collective learning-by-doing, and stress the role of IPR in the internalization of learning spillovers. There are however two differences.

The first is that they focus their policy discussion on patent length, whereas we consider issues which are more relevant to the current debate on international technology transfer (imperfect enforcement of IPR in particular). The second difference is more crucial and concerns the impact of the technology in the final

\footnotetext{
${ }^{3}$ More recent papers like Cabral and Dezso (2008) or Kristiansen (2006) also take into account strategic interaction on the supply side between rival technology providers.
} 
product market. They assume that the new technology is required to start production. In this context, the patent holder always sells the technology to a single adopter, so that monopoly rents can be extracted in the product market. In contrast with David and Olsen (1992), we do not consider drastic innovations. In our model, potential adopters initially operate with an old technology and they can continue to do so even if some competitors purchase the new one. ${ }^{4}$

Katz and Shapiro (1987) analyze R\&D competition between two firms. At the core of their argument is the weakness of patent protection. If imitation is possible, a firm may prefer innovation by its rival. In this context, R\&D competition can become a waiting game rather than a race. The basic mechanism is therefore very similar to ours. Innovating first generates a positive externality which delays further innovation. But they analyze innovation, not diffusion. This is the second important difference with our paper. We show that a patent holder organizes diffusion through inter-temporal price discrimination whereas in Katz and Shapiro's work there is no external firm that can coordinate innovation. ${ }^{5}$

Finally, our work draws interesting parallels with the literature on network externalities (for instance see Katz and Shapiro, 1986, or Choi, 1994). Like us this literature studies diffusion path with externalities. But network externalities are significantly different: what matters for a given purchaser of a network good is the final size of the network, not its size at the date when it joins the network. In other words, externalities are two-way: from early to late adopters, and viceversa. As a result, the second mover advantage is not as big with network effects as with learning spillovers. This furthermore causes expectations on future adoptions to play a crucial role in networks.

Another similarity is the key role of these firms which can organize diffusion:

\footnotetext{
${ }^{4}$ Note that both approaches rule out strategic effects in the product market.

${ }^{5} \mathrm{R} \& \mathrm{D}$ coordination might be the role of a public regulator. In fact, their model is a specific application of Arrow's idea that innovation is a public good.
} 
the patent holder in our paper, the technology "sponsor" in the papers on network externalities. Yet the network literature mainly focuses on competition between sponsors, whereas we study how the legal context affects the patent holder's strategies.

\section{Model and social optimum}

In this section, we present a simple model in continuous time which describes the adoption by $n$ symmetric firms ${ }^{6}$ of a competitively-supplied technology. In the following sections, we introduce the alternative assumption that the technology is sold by an exclusive provider.

\subsection{Firms' payoffs}

At the beginning of the game, firm $i$ derives a market profit $\pi^{\circ}$ per time period. When the firm adopts the technology, this profit changes. Let $\pi$ denote the profit flow after adoption. The technology can increase the profit $\left(\pi>\pi^{\circ}\right)$ or decrease it $\left(\pi \leq \pi^{\circ}\right)$. To facilitate the presentation, we maintain throughout that $\pi^{\circ}=0$. As mentioned in introduction, technology adoption by a given firm does not affect other firms' profits. This either means that firms operate in different local markets, or that the technology does not affect marginal production costs - and therefore prices - in the product market. We discuss in Section 8 how imperfect competition could alter our results.

In this first version of the model, the technology market is competitive, implying that the price equals the marginal cost of technology supply. Without any loss of generality we normalize the marginal cost to zero. ${ }^{7}$

\footnotetext{
${ }^{6}$ As firms are symmetric, we could restrict the model to two firms. But some results would not be robust. In particular, Proposition 3 would be different: a Pigovian subsidy never implements the social optimum when $n=2$.

${ }^{7}$ Another interpretation of the setup is to assume that the marginal cost is positive, but included in the market profit $\pi$.
} 
Adopting the technology entails a fixed cost borne by the adopters. To capture the learning spillovers following previous adoptions, we make the assumption that the adoption cost starts decreasing endogenously after the first adoption. This is the key assumption of our model. This externality creates a second-mover advantage as followers reap these benefits. In most previous models of technology diffusion, the adoption cost decreases with time for exogenous reasons so that this effect cannot be obtained (see for instance Reinganum, 1981, and Fudenberg \& Tirole, 1985).

Formally, $c$ is the cost for the first adopter while a follower bears $c e^{-\lambda d}$ where $d$ is the time that has passed since the first adoption. When $\lambda>0$, there is an incentive for the followers to delay adoption in order to benefit from the leader's experience. When $\lambda=0$, there is no positive externality of adoption. In the following, we refer to $\lambda$ as the learning rate.

In this setting, the firm adopting first is the only generator of the externality. More realistically, we could assume that the adoption cost also decreases with the number of firms having adopted previously. But this would be far less tractable and we do not see how it could qualitatively alter our results.

We now express the net present profits. Let $T$ denote the date of the first adoption and $v^{L}$ the net profit of the first adopter, discounted at time $T$. We have

$$
v^{L}=-c+\int_{0}^{\infty} \pi e^{-r t} d t=\frac{\pi}{r}-c
$$

Turning next to followers, they derive zero market profit $\left(\pi^{\circ}=0\right)$ before adoption (between $T$ and $T+d$ ). After adoption, they derive the market profit $\pi$. Their net present payoff at time $T$ is thus

$$
v^{F}(d) \equiv-c e^{-(r+\lambda) d}+\int_{d}^{\infty} \pi e^{-r t} d t=e^{-r d}\left(\frac{\pi}{r}-c e^{-\lambda d}\right)
$$




\subsection{Timing}

We consider a dynamic game in continuous time where the $n$ firms decide whether and when they purchase the technology. In doing so, they take into account the other firms' adoption decisions. The game has two stages:

- The first stage determines the date $T$ of the first adoption.

- The second stage starts at time $T$ and concerns the $n-1$ firms that did not adopt in the first stage. More precisely the follower indexed $i$ selects the adoption time $T+d_{i}$.

The fact that firms makes strategic adoption decisions strongly influences the results. David and Olsen (1992) also consider adoption externalities, but they do not allow for non-market strategic interactions on the technology demand side. Only Mariotti (1992) allows for such interactions in a simple discrete time model. We substantially extend his analysis by considering a richer set of strategies in a continuous time model.

\subsection{The socially optimal path of adoption}

The ultimate objective of our paper is to derive policy lessons about technology diffusion. Therefore, we need to select a definition of social welfare. We choose to equate social welfare to the sum of firms' profits $^{8}$. Although this approach does not take into account the consumer surplus, it is suitable in that our welfare analysis is entirely focused on diffusion between firms. In section 8 , we will see that this simplification does not affect qualitatively our results. For similar reasons, we also ignore the impact of diffusion on the incentives to innovate. we Let us now derive the first best diffusion path.

\footnotetext{
${ }^{8}$ Including the patent holder's profit in the next sections.
} 
As the level of profits derived by the followers is affected by the leader's behavior, we analyze backwards by considering the last stage first. Our goal is to identify the socially optimal delay $d^{*}$ after the first adoption.

As followers do not generate any externality, the socially optimal delay is simply the solution of the followers' maximization program:

$$
\max _{d} v^{F}(d)
$$

under the constraint that adopting improves the social benefit of adoption relative to the status quo: $v^{F}(d)>0$.

Substituting (2) and solving this program for $d$ yields:

$$
d^{*}=\left\{\begin{array}{l}
\frac{1}{\lambda} \ln \frac{(r+\lambda) c}{\pi} \text { if } v^{L}<\lambda c / r \\
0, \text { otherwise }
\end{array}\right.
$$

Equation (4) says that the followers should adopt immediately $\left(d^{*}=0\right)$ if the technology profitability - reflected by $v^{L}-$ is high compared to the discount rate $r$ and the learning factor $\lambda$. But the lower the technology profitability and the faster the decrease of the adoption cost over time, the less desirable an immediate adoption will be.

Moving backwards, we now consider the first adoption. Significantly, this adoption generates a positive externality among the followers. Hence, the first adoption is optimal if the social welfare induced by this decision and the $n-1$ subsequent adoptions is more than the welfare without any adoption. Formally, this condition can be written:

$$
v^{L}+(n-1) v^{F}\left(d^{*}\right) \geq 0
$$

In addition to this, adoption should take place at $T=0$ because discounting 
makes any delay socially detrimental once (5) holds true. More precisely, we easily show the following:

Proposition 1 The socially optimal diffusion path depends on the technology's profitability reflected by $v^{L}$ as follows:

1. If $v^{L}<-(n-1) v^{F}\left(d^{*}\right)$, no adoption should take place.

2. If $-(n-1) v^{F}\left(d^{*}\right) \leq v^{L}<\lambda c / r$, a first adoption should occur at $T=0$ and the $n-1$ following adoptions at $T+d^{*}$. In this case $d^{*}$ is strictly positive $\left(d^{*}=\frac{1}{\lambda} \ln \left(\frac{r+\lambda}{V}\right)\right)$.

3. If $v^{L} \geq \lambda c / r$, all firms should adopt simultaneously at $T=0$.

Proof. By plugging (4) in (5) and rearranging, we get $v^{L}>-(n-1) v^{F}\left(d^{*}\right)$ if $v^{L}<\lambda c / r$ and $v^{L} \geq 0$ if $v^{L} \geq \lambda c / r$. It is obvious that the second condition is always satisfied as $\lambda c / r \geq 0$. Furthermore $-(n-1) v^{F}\left(d^{*}\right)<\lambda c / r$. The proposition directly follows from this.

\section{Competitive supply}

We now investigate whether the decentralized path of diffusion implements the social optimum when the technology market is competitive. Given the existence of a positive externality, the answer is expectedly negative as the early adopters neglect learning benefits. However, we will see that the positive externality induces two types of inefficiency in our dynamic setting: the traditional underprovision problem, and a coordination problem leading to socially-detrimental delays of adoption. 


\subsection{Equilibrium}

Reasoning backward, consider first how followers react after one firm has adopted the technology. The analysis is straightforward, as the welfare maximization program (3) and the followers' profit maximization program are the same. They thus adopt with a delay $d^{*}$. The interpretation is very simple. As followers' decisions entail zero externality, the decentralized outcome is socially optimal.

Moving backwards, we consider next the problem of the first adoption. We randomize the adoption decision at each time period $[t, t+d t)$ in order to derive equilibriums in mixed strategies. As we will see, this setup allows us to determine endogenous delays of adoption. As mentioned above, this extends the analysis carried out by Mariotti (1992) in a continuous setting where all mixed strategies are allowed.

Let $x_{i} d t$ denote the probability that firm $i=1, . ., n$ adopts the technology between $t$ and $t+d t$, provided that the technology has not been adopted yet at time $t$. Using these notations, a pure strategy consists in a probability of either $x_{i} d t=1$ or $x_{i} d t=0$, that is, firm $i$ adopts (or not) in the short time interval $[t, t+d t]$. A mixed strategy is $0<x_{i} d t<1$.

Firm $i$ 's expected payoff at any time $t$ is given by the following Bellman equation:

$$
\begin{aligned}
P_{i}(t) & =v^{L} x_{i} d t+\left(1-x_{i} d t\right)\left[1-\prod_{k \neq i}\left(1-x_{k} d t\right)\right] v^{F}\left(d^{*}\right) \\
& +\left[\prod_{k=1}^{n}\left(1-x_{k} d t\right)\right] e^{-r d t} P_{i}(t+d t)
\end{aligned}
$$

In this expression, the first term $v^{L} x_{i} d t$ is firm $i$ 's expected payoff of adoption in time interval $[0 ; 0+d t]$. The second term is the expected payoff if firm $i$ does not adopt in that interval, which occurs with a probability $\left(1-x_{i} d t\right)$, and if at least one firm $k \neq i$ adopts in the same period, which occurs with a probability 
$1-\prod_{k \neq i}\left(1-x_{k}(t)\right)$. Finally, the last term is the payoff when nobody adopts between $t$ and $t+d t$. In this case, firm $i$ derives $P_{i}$ in the next period which is discounted.

In the appendix we solve the game for equilibriums in pure and mixed strategies. This leads to:

Proposition 2 Depending on payoffs, we observe different equilibriums:

1. If $v^{L}<0$, then $x_{i} d t=0$ for any $i=1, . ., n$ and no firm ever adopts the technology.

2. If $0 \leq v^{L}<\lambda c / r$, there are:

(a) $n$ equilibriums in pure strategies, whereby one firm adopts at $T=0$ and the others follow at $T+d^{*}$ with $d^{*}>0$.

(b) one symmetric equilibrium in mixed strategies in which each firm $i=1, . ., n$ adopts with a probability

$$
\hat{x}=\frac{r v^{L}}{[n-1]\left[v^{F}\left(d^{*}\right)-v^{L}\right]}
$$

so that the expected delay until the first adoption is:

$$
E(T)=\left(\frac{n-1}{n}\right) \frac{v^{F}\left(d^{*}\right)-v^{L}}{r v^{L}}
$$

Once a firm has adopted, the others follow with a delay $d^{*}>0$.

3. If $v^{L} \geq \lambda c / r$, then there are $n$ equilibriums in which one firm adopts at $T=0\left(x_{i} d t=1\right)$ and all other firms follow immediately $\left(x_{j} d t \in[0,1]\right.$, $\forall j \neq i)$.

Proof. See Appendix. 
This proposition is the first key result of the paper. The intuition underlying Case 1 and Case 3 is obvious. In Case 1, the first adoption never takes place because the technology is not profitable enough $\left(v^{L}<0\right)$. In Case 3 , the first adoption is very profitable $\left(v^{L} \geq \lambda c / r\right)$ and the other firms immediately follow because the technology is so profitable.

The most interesting possibility is Case 2 where we have multiple equilibriums. Here, the technology value is sufficiently high for making adoptions profitable. But it is too low for triggering simultaneous adoptions $\left(d^{*}>0\right)$. Followers prefer delaying adoption because the benefit of waiting, in terms of reduced adoption costs, is higher than the profit loss due to delayed adoption. Another way to look at this is that the externality of adoption captured by the learning parameter $\lambda$ is large enough to delay subsequent adoptions.

Note that we have $v^{L}<v^{F}\left(d^{*}\right)$, meaning that the incentive to preempt is weaker than the incentive to follow. This looks like a "chicken game" where all firms are willing to adopt but have conflicting views on who should go first. As usual in chicken games, this generates a coordination problem leading to multiple Nash equilibriums.

The equilibriums in pure strategies (2a) are not very plausible because all firms have an incentive to free ride on the first adoption so that no firm wishes to adopt first at $T=0$. In that case, we can reasonably expect strategic delays in the first adoption. This corresponds to the symmetric equilibrium in mixed strategies $(2 \mathrm{~b})$ where the expected date of the first adoption $E(T)$ is strictly positive. In the rest of the paper, we continue to focus on this equilibrium. Note that, given (8), the larger the gap between the leader's payoff $v^{L}$ and the followers' payoff $v^{F}$, the longer the delay before the first adoption. 


\subsection{Social welfare}

We are now able to investigate the welfare properties of the competitive scenario. To begin with, recall that the followers' decision is optimal as it does not generate any externality of adoption. Turning next to the leader, Proposition 2 tells us that the first adoption will take place iff $v^{L} \geq 0$. Unsurprisingly, the comparison with the optimality condition (5) shows that $v^{L} \geq 0$ is too strict to induce socially optimal decisions by the leader. This is the standard result that positive externalities lead to too few adoptions.

Interestingly, a second inefficiency exists in the particular case where $d^{*}>$ 0. Proposition 2 predicts an equilibrium in mixed strategies, involveing a delay in the first adoption while the optimal date is $T^{*}=0$.

We summarize these findings below.

Lemma 1 Diffusion is not socially optimal when the technology market is competitive. More precisely,

1. When $v^{L} \in\left(-(n-1) v^{F}\left(d^{*}\right), 0\right]$, the first adoption should take place at $T^{*}=0$ but it never occurs.

2. When $v^{L} \in(0, \lambda c / r)$, the first adoption is delayed in the mixed strategy equilibrium while the optimal adoption date is $T^{*}=0$.

In short, the social inefficiency exclusively concerns the leader: diffusion starts either too late or never.

\subsection{Adoption subsidies}

A canonical solution to the externality problem is the Pigovian subsidy where the leader receives a payment equal to the positive externality generated by its adoption. We will see that this solution does not always restore efficiency in our setup. 
The analysis focuses on a scheme based on the adoption rank. This means in particular that we rule out subsidies that would be based on adoption dates. We do so for realism: in practice, regulators cannot know when it is $T=0$, or any other date, as there is no clear beginning of the diffusion process. ${ }^{9}$

We consider a scheme where all firms that adopt first (simultaneously) enjoy the same premium. Let $s$ denote this subsidy. We obtain a new participation constraint $v^{L}+s \geq 0$ whereas the optimality condition is $v^{L}+(n-1) v^{F}\left(d^{*}\right) \geq 0$. It is then immediate that a premium $s^{*}$ such that

$$
s^{*} \equiv(n-1) v^{F}\left(d^{*}\right)
$$

solves the under-provision problem. This is the classical Pigovian subsidy where the leader that generates a positive externality receives a payment internalizing the full social benefit of adoption by the $(n-1)$ followers.

But the problem is that the Pigovian subsidy $s^{*}$ does not always solve the coordination problem. From (8), we know that the longer the delay, the larger the gap between the followers' and the leader's payoff. Granting the premium $s^{*}$ to the leader thus mitigates the problem as it reduces the payoff difference. Whether it is sufficient to solve it completely depends on the subsidy level, and thus on the size of the externality. More precisely, two cases are possible:

1. If $v^{L}+s \geq v^{F}\left(d^{*}\right)$, which is equivalent to $v^{L}+(n-2) v^{F}\left(d^{*}\right) \geq 0$, the leader adopts at $T=0$. However, all firms will do the same as waiting is less profitable than adopting immediately. This is inefficient as followers should delay for $d^{*}>0$. This distortion can be eliminated simply by restricting the reward to a single firm. Once this firm gets the premium, the other ones' best reply is to follow after an optimal delay $d^{*}$.

\footnotetext{
${ }^{9} \mathrm{Or}$, at least, the starting date is specific to each technology, and sector so that regulators cannot know it (or they might eventually be informed ex post, which is useless).
} 
2. If $v^{L}+s<v^{F}\left(d^{*}\right)$, there remains a gap between leader's and followers' payoffs so that $T>0$. Then followers make efficient decisions by adopting after a delay $d^{*}$. This inefficient delay can be reduced by increasing the size of the subsidy $\left(s>s^{*}\right)$. But a higher subsidy rate will never align the participation constraint $v^{L}+s \geq 0$ with the optimality condition $v^{L}+(n-1) v^{F}\left(d^{*}\right) \geq 0$.

We state these results as:

Proposition 3 Granting a Pigovian subsidy $s^{*}=(n-1) v^{F}\left(d^{*}\right)$ to a firm that adopts first implements the social optimum iff $s^{*} \geq v^{F}\left(d^{*}\right)-v^{L}$, or equivalently iff $v^{L} \geq-(n-2) v^{F}\left(d^{*}\right)$. The premium should be granted to a single firm in the case where several firms want to take the lead.

If $v^{L}<-(n-2) v^{F}\left(d^{*}\right)$, the use of a subsidy improves social welfare but fails to implement the first best optimum.

Proof. See the appendix.

The intuition is simple. When first adoption entails a loss $\left(v^{L}<0\right)$ and the social benefit of technology diffusion is so weak that it hinges on the last follower (it would be negative with one less follower), the premium is not large enough to compensate for the opportunity cost of moving first. Hence a positive delay remains before the first adoption.

\section{Supply under perfect patent protection}

So far, we have assumed that the technology was competitively supplied. In this section we analyze the alternative case of a proprietary technology sold by the patent holder. In the competitive case, the technology price is uniform as the cost of supplying that technology - which we have normalized to zero - 
does not vary over time. In contrast with this, the patent holder in a monopoly position can discriminate between firms. We can expect that, in some cases, it will offer a rebate to the leader if the profits made with followers outweigh this initial loss. Given Proposition 2, this will improve welfare by reducing the possible gap between the followers' and the leader's payoffs.

\subsection{Technology price for the followers}

Reasoning backward, we study first the monopolist's pricing strategy, provided that it has already sold the technology to at least one firm at time $T$. Let $p^{F}(d)$ denote the technology price at date $T+d$. Note that we allow the monopolist to change the price over time. We will also assume that the provider can revise the price at any moment, and can therefore not commit ex ante to a price path.

It is easily shown that:

Lemma 2 The equilibrium price path is the following: the provider charges a price above the followers' reservation price before $T+d^{*}$ to prevent adoption. That is, $p^{F}(d)>e^{r d} v^{F}(d)$ for $d<d^{*}$. It then sets the reservation price $\hat{p}^{F}=$ $e^{r d *}\left[v^{F}\left(d^{*}\right)\right]$ at time $t=T+d^{*}$, and this induces adoption.

Proof. Assume first that the followers have not bought the technology at time $t \geq T+d^{*}$. The best strategy for the monopolist is then to sell the technology at the reservation price $v^{F}(d)$, and to do so immediately at $t=T+d^{*}$ as $v^{F}(d)$ decreases with $d$ when $d>d^{*}$. Turning next to the adopters, recall that they are price takers. They thus decide only when they purchase the technology. In this respect, they have no reason not to purchase at $T+d^{*}$ as they anticipate their surplus is $v^{F}(d)-e^{-r d} p^{F}=0$ at any $t>T+d^{*}$. Selling at the reservation price at time $T+d^{*}$ yields the highest profit to the patent holder as $v^{F}(d)$ is maximized. Therefore it will not sell the technology in the interval $\left[T, T+d^{*}\right)$ by setting a price above the reservation level. 
This result is highy intuitive. The provider sets the price at the reservation level and it does so when $d=d^{*}$ as this maximizes $v^{F}$, the followers' profit excluding price.

Note that the lack of ex ante commitment to a price path does not prevent the full extraction of followers' surplus by the monopolist. This is not that obvious as a patent is a durable good. Based on the Coase conjecture, some may object that intertemporal price discrimination is not a credible strategy for the monopolist. But discrimination works the other way round in our setup: due to learning benefits, the higher price is for the followers, not for the leaders. A potential early adopter therefore has no reason to wait for a reduced price.

Importantly, the technology provider is able to induce adoption at the socially optimal date. From a social welfare point of view, competition or monopoly thus yield the same outcome at the second stage. This will obviously simplify the welfare comparison of the two regimes.

\subsection{Leader's technology price}

Moving backwards, we now study the price charged to the first adopter. Ideally, the patent holder wants to sell the technology as soon as possible $(T=0)$, and at the highest feasible price $\left(p^{L}=v^{L}\right)$. Both objectives are compatible: when $p^{L}=v^{L}$, the leader's payoff is the same as the follower's: $v^{L}-p^{L}=$ $v^{F}\left(d^{*}\right)-e^{-r d *} p^{F}=0$, implying that $T=0$.

This pricing strategy is profitable if $\Pi=p^{L}+(n-1) p^{F} \geq 0$. This exactly matches with the optimality condition: $v^{L} \geq-(n-1) v^{F}\left(d^{*}\right)$. Therefore,

Proposition 4 An exclusive technology provider sells the technology at prices $p^{L}=v^{L}$ and $p^{F}=v^{F}\left(d^{*}\right)$ if $v^{L} \geq(n-1) v^{F}\left(d^{*}\right)$. This implements the socially optimal path with a first adoption at $T=0$ and subsequent ones with a delay $d^{*}$. 
This is a key result of the paper. As compared to adoption subsidies which do not implement the social optimum when learning externalities are low (see Proposition 3), the patent owner is always able to reach the social optimum. IP regulation is potentially a more powerful policy instrument to internalize learning spillovers.

\section{Imperfect enforcement of IPR}

The previous result decisively hinges upon the fact that the patent holder reaps the followers' entire surplus, thereby fully internalizing the learning external benefits. This is clearly a limit case. In reality various factors constrain its pricing behavior. In this subsection we consider one of those: the fact that IP rights are imperfectly enforced. Particularly in international contexts, more or less costly solutions to access patented technologies without paying royalties always exists, and this generates a great deal of policy discussions.

In this section we compare an imperfectly-enforced patent regime with the competitive scenario. More specifically, we assume that, once the technology has been introduced in the country - that is, sold to at least one firm -, followers or local technology providers can imitate it in order to avoid paying royalties. Imitation is costly, however. Each imitator incurs a cost $f$ which consists of the expected penalty for non-compliance with patent regulation plus the imitation cost itself (e.g., the resources devoted to reverse engineering).

Imitation limits the patent holder's ability to charge a high price to the followers. Moreover, imitation is arguably more costly when the technology has not yet been introduced in the country (or in a market, more generally), that is, before the first adoption in our setting. We capture this difference between a leader and a follower with the clear-cut hypothesis that imitation is possible only for the latter. 


\subsection{Technology price for the followers}

The monopolist is constrained by the risk of imitation as each follower can choose either to buy the technology or to imitate it at cost $f$. Under the imitation scenario, each follower maximizes

$$
v^{F}(d)-f e^{-r d}=e^{-r d}\left(\frac{\pi}{r}-f-c e^{-\lambda d}\right)
$$

By analogy with (4), it thus imitates with the delay

$$
\begin{aligned}
& d^{f}= \\
& \begin{cases}0 & \text { if } f \leq v^{L}-\frac{\lambda}{r} c \\
\frac{1}{\lambda} \ln \left[\frac{c(r+\lambda)}{\pi-r f}\right] & \text { if } \quad v^{L}-\frac{\lambda}{r} c<f<v^{L}+c \\
\infty \text { (no imitation) } & \text { if } \quad f \geq v^{L}+c\end{cases}
\end{aligned}
$$

Note that $d^{f}$ increases with $f$ : followers react to an increase of $f$ by waiting more in order to mitigate the cost of adoption. Formally, this means that $d^{f}$ is less than $d^{*}$, the (first-best) delay in the competitive case.

We are now able to write the imitation constraint. A necessary condition for the technology to be sold at price $p^{F}(d)$ is

$$
v^{F}(d)-e^{-r d} p^{F}(d) \geq v^{F}\left(d^{f}\right)-f e^{-r d^{f}}
$$

We now derive the pricing strategy of the technology provider in equilibrium:

Lemma 3 The equilibrium price path is the following: the provider charges a price above the followers' reservation price before $T+d^{*}$ to prevent adoption. That is, $p^{F}(d)>e^{r d}\left[v^{F}(d)-v^{F}\left(d^{f}\right)\right]+f e^{-r\left(d^{f}-d\right)}$ for $d<d^{*}$. It then sets the price $\hat{p}^{F}=e^{r d *}\left[v^{F}\left(d^{*}\right)-v^{F}\left(d^{f}\right)\right]+f e^{-r\left(d^{f}-d *\right)}$ at time $t=T+d^{*}$, and this induces adoption. 
Proof. See in Appendix.

This result is quite intuitive. The provider sets the price at the reservation level and it does so when $d=d^{*}$ as this maximizes $v^{F}$, the followers' profit excluding price.

Importantly, the technology provider is still able to induce adoption at the socially optimal date. From a social welfare point of view, competition and monopoly thus yield the same outcome at the second stage. This will obviously simplify the welfare analysis.

Note also that followers' payoff is $v^{F}\left(d^{*}\right)-e^{-r d *} \hat{p}^{F}=v^{F}\left(d^{f}\right)-f e^{-r d^{f}}$ in equilibrium. We know from (10) that $d^{f}=\infty$ if $f \geq v^{L}+c$. In this case the follower's payoff is thus zero and $\hat{p}^{F}=e^{r d *} v^{F}\left(d^{*}\right)$. This corresponds to the perfect enforcement case previously analyzed. Imitation is not a constraint and inter-temporal discrimination allows the social optimum to be reached.

If $f<v^{L}+c$, the price is less than $v^{F}\left(d^{*}\right)$ and the followers' payoff is strictly positive. Therefore the patent owner does not internalize all learning benefits. This will generate inefficiencies in the first stage, which we consider know.

\subsection{Technology price for the leader}

When $f<v^{L}+c$, the analysis is more complicated than in the perfect enforcement case. No firm ever adopts the technology if $p^{L}>v^{L}$. In the alternative case $\left(p^{L} \leq v^{L}\right)$, we can deduce from Lemma 1 the leader's response:

- It delays adoption if $v^{L}-p^{L}<v^{F}\left(d^{*}\right)-\hat{p}^{F} e^{-r d *}$. Accordingly the provider's expected profit is:

$$
\Pi=\int_{0}^{\infty} n \hat{y} e^{-n \hat{y} t}\left(p^{L}+(n-1) \hat{p}^{F} e^{-r d^{*}}\right) e^{-r t} d t
$$


where $\hat{y}$ is the leader's probability of adoption. This probability can easily be derived from equation (7):

$$
\hat{y}=\frac{r\left(v^{L}-p^{L}\right)}{[n-1]\left[v^{F}\left(d^{*}\right)-\hat{p}^{F} e^{-r d^{*}}-v^{L}+p^{L}\right]}
$$

- It adopts at $T=0$ if $v^{L}-p^{L} \geq v^{F}\left(d^{*}\right)-\hat{p}^{F} e^{-r d *}$ so that the provider's profit is

$$
\Pi=p^{L}+(n-1) \hat{p}^{F} e^{-r d^{*}}
$$

In Appendix 9.4, we solve the provider's profit maximization program max $\Pi$ subject to $p^{L} \leq v^{L}$ and $\Pi \geq 0$ and we obtain:

Proposition 5 Equilibrium prices and diffusion paths under imperfect enforcement of IPR are the following:

- The technology provider does not sell the technology when

$$
v^{L}<-(n-1) \hat{p}^{F} e^{-r d^{*}}
$$

- The equilibrium price is given by the condition $X\left(p_{L}\right)=0$ when

$$
-(n-1) \hat{p}^{F} e^{-r d^{*}} \leq v^{L}<\frac{2 n-1}{n-1} v^{F}\left(d^{*}\right)-\frac{n^{2}}{n-1} \hat{p}^{F} e^{-r d^{*}} .
$$

with

$X\left(p^{L}\right)=\left(v^{L}-p^{L}\right)^{2}+(n-1)\left(v^{F}\left(d^{*}\right)-\hat{p}^{F} e^{-r d^{*}}\right)\left(v^{L}-2 p^{L}-(n-1) \hat{p}^{F} e^{-r d^{*}}\right)$

In this case, the first adoption is delayed $(E(T)>0)$. 
- The equilibrium price is $\hat{p}^{L}=v^{L}-v^{F}\left(d^{*}\right)+\hat{p}^{F} e^{-r d^{*}}$ when

$$
v_{L} \geq \frac{2 n-1}{n-1} v^{F}\left(d^{*}\right)-\frac{n^{2}}{n-1} \hat{p}^{F} e^{-r d^{*}}
$$

and this induces an immediate adoption $(T=0)$.

Proof. See Appendix.

The overall pattern is similar to that of the competitive case, but with different thresholds. When $v^{L}<0$, adoption will not take place if the patent owner's profit from the followers' adoption is not sufficient to compensate for the cost of subsidizing the first adoption. For larger values of $v^{L}$ (including $v^{L}=0$ ), adoption takes place after an initial delay $E(T)>0$, reflecting the fact that the patent owner does not entirely internalize the surplus of technology diffusion. Finally, all firms will adopt immediately at $T=0$ when the profit of a first adoption $v^{L}$ is sufficiently large as compared to the learning externality. We now compare the welfare effects of this policy regime with the competitive case.

\subsection{Welfare comparison}

Recall that the second-stage outcomes are the same under competitive supply and imperfectly-enforced IPR: the followers adopt after the socially optimal delay $d^{*}$. As a result, we need to analyze only the first stage. Table 1 presents the results on initial delays given by Propositions 1, 2 and 4. We distinguish the social optimum $(*)$, the path when the technology is purchased in a competitive market $^{10}(\mathrm{C})$, and the path when the technology is patented (IP). In this table, $A \equiv \frac{2 n-1}{n-1} v^{F}\left(d^{*}\right)-\frac{n^{2}}{n-1} \hat{p}^{F} e^{-r d^{*}}$.

\section{Table 1: Diffusion paths as a function of $v^{L}:(*)$ Social optimum;}

\footnotetext{
${ }^{10}$ Note that imitation was not introduced in the analysis of the competitive scenario. But this does not alter any results as the zero price obviously eliminates the incentives to imitate.
} 
(PC) Perfect competition; (IP) Imperfect enforcement of IPR

\begin{tabular}{|l|l|l|l|}
\hline & No diffusion & Diffusion with $E(T)>0$ & Diffusion with $T=0$ \\
\hline$*$ & $v^{L} \leq-(n-1) v^{F}\left(d^{*}\right)$ & $\varnothing$ & $v^{L}>-(n-1) v^{F}\left(d^{*}\right)$ \\
\hline $\mathrm{C}$ & $v^{L} \leq 0$ & $0<. \leq \lambda c / r$ & $v^{L}>\lambda c / r$ \\
\hline $\mathrm{IP}$ & $v^{L} \leq-(n-1) \hat{p}^{F} e^{-r d^{*}}$ & $-(n-1) \hat{p}^{F} e^{-r d^{*}}<. \leq A$ & $v^{L}>A$ \\
\hline
\end{tabular}

Under patenting, equilibrium paths centrally depend on $\hat{p}^{F}$ which is itself mostly determined by the imitation constraint. We have already seen that IP and $*$ coincides when $f \geq v^{L}+c$. We now consider the other extreme case where imitation is free $(f=0)$.

$>$ From $f=0$, it follows that $\hat{p}^{F}=0$, so that the condition for having diffusion is $v^{L}>0$, just like under perfect competition: as imitation precludes profits being made by the followers, the incentive to subsidize a first adoption vanishes.

The condition determining whether no delays occur in equilibrium is now:

$$
v^{L} \geq \frac{2 n-1}{n-1} v^{F}\left(d^{*}\right)
$$

As $\frac{2 n-1}{n-1} \in[2,3]$ for $n \geq 2, \frac{2 n-1}{n-1} v^{F}\left(d^{*}\right)>v^{F}\left(d^{*}\right)$. From $v^{L} \leq v^{F}\left(d^{*}\right)$ it follows that this condition is never satisfied: the leading firm systematically delays its adoption.

How does this compare to the competitive scenario? It is clear that perfect competition yields a higher welfare when $v^{L} \geq \lambda c / r$ as $T=0$ in this case. When $v^{L}<\lambda c / r$, the difference between adoption probabilities (7) and (12) is

$$
\hat{x}-\hat{y}=\frac{r}{n-1}\left(\frac{v^{L}}{v^{F}\left(d^{*}\right)-v^{L}}-\frac{r v^{L}-p^{L}}{[n-1]\left[v^{F}\left(d^{*}\right)-v^{L}+p^{L}\right]}\right)
$$


which is positive because $p^{L} \geq 0$. Competitive supply still outperforms the IP regime.

We generalize these findings in the following:

Proposition 6 When imitation limits the patent holder's ability to increase the price for the followers $\left(f<v^{L}+c\right)$, a level of imitation cost $f^{\circ}$ exists, so that perfect competition is socially preferable to patenting when $f<f^{\circ}$.

Proof. We have already analyzed the two cases $f \geq v^{L}+c$ and $f=0$. The generalization directly follows from the fact that $\hat{p}^{F} e^{-r d^{*}}$ decreases from $v^{F}\left(d^{*}\right)$ to zero with $f$ in the interval $\left(0, v^{L}+c\right)$.

This proposition yields the final message of the paper: in the presence of learning spillovers, the competitive supply of technology might be socially preferable to a poorly enforced patent regime. This is so because prices are still discriminated when imitation is cheap, but in the wrong way: the leader pays a higher price than the followers (who can imitate at low cost).

\section{Consumer surplus and imperfect competition}

The model drastically simplifies the product market on which the firms compete for we want to focus on technology diffusion and the role of patenting. In our view, two simplifying assumptions are critical: We have not included the consumer surplus in the social welfare function and there is no strategic effect of technology adoption on the product market. In this section, we briefly discuss how relaxing these asumptions would affect our results.

\subsection{Consumer surplus}

It is rather straightforward to show that introducing consumer surplus would not change our results qualitatively. Assume that consumers derive a surplus 
$w^{\circ}$ before the first adoption (which could be normalized to zero as we did for $\pi^{\circ}$ ), a per-time period surplus $w_{1}$ between $T$ and $T+d$ and $w$ after $T+d$. We assume that the firms do not capture all the surplus gererated by the technology adoption, so that technology diffusion also generates a surplus for consumers: $w>w_{1}>w^{\circ}$. These new assumptions do not change the diffusion path as $w_{1}$ and $w$ are reduced forms of equilibrium consumer surpluses, which are thus not appropriated by firms. They only affect the social welfare function. It is then easy to anticipate that:

- The socially optimal delay $d^{* *}$ after the first adoption becomes shorter than the delay $d^{*}$ selected by the followers in the base model as each adoption generates an additional benefit $w_{1}-w^{\circ}$ or $w-w^{\circ}$ per time period.

- The socially optimal delay before the first adoption continues to be either $\infty$ or 0 like in Proposition 1 but the threshold changes: diffusion should intervene for a broader set of parameters as the first adoption generates an additional benefit

$$
\Delta w=\left(1-e^{-r d}\right) \frac{w_{1}-w^{\circ}}{r}+e^{-r d} \frac{w-w^{\circ}}{r}
$$

As diffusion paths remain identical, this simply changes the benchmark againts which we assess each equilibrium diffusion path. This modification does not modify the welfare ranking between the scenario with competitive technology supply and with patenting as all equilibrium delays are now too long in all scenarios as compared to the social optimum 


\subsection{Imperfect competition}

In constrast, introducing strategic effects on the product market deeply modifies diffusion paths as it alters adoption incentives. Imperfect competition would imply that the leader derives a higher market profit during the period when he is the sole user of the technology, while the followers reduce their profits in the meantime. Then all firms - the leader and the followers - derive the same market profit when the technology is universally adopted.

This means that imperfect competition introduces a first-mover advantage - $v^{L}$ increases - which goes against the second-mover advantage driven by learning spillovers. This is reinforced by the fact that $v^{F}$ is reduced as followers derive a lower profit between $T$ and $T+d$. Accordingly they adopt the technology earlier than in the base model. It is perfectly possible that, in some cases, the preemption effect will more than compensate learning benefits (that is, $v^{L}>v^{F}$ ) so that the initial delay will disappear.

What about the welfare impacts? There would not be any general answers as there are two contradictory effects: Imperfect competition mitigates the learning externality problem but it reduces output on the product market. In fact, the final outcome will ultimately depend on parameters such as demand elasticity or the production cost functions which determine the market equilibrium.

Nevertheless, although introducing imperfect competition can dramatically change the story if the preemption effect dominates the learning externality effect, it simply hides the mechanism analyzed in our paper.

\section{Conclusion}

Ensuring the diffusion of technologies in developing countries is a major policy challenge in which there is still uncertainty as regards the appropriate policy 
tools. In particular, two contrasting options can be considered. On the one hand, the competitive supply of technology eliminates price barriers to its diffusion; on the other, patent protection raises such barriers but also enables monopolistic providers to organize technology diffusion in a centralized and maybe more efficient way.

We have compared the respective merits of different policy options when it comes to diffusing technologies featured by learning externalities. When the technology market is competitive, a first message is that learning spillovers generate two types of inefficiency. The first is the traditional under-provision problem. The second is a coordination problem. Even when the first adoption is profitable, firms may have an incentive to wait and to adopt after the first adoption in order to benefit from learning externalities. Such strategies then generate a socially wasteful delay until the first adoption of the technology.

We have shown that the canonical solution to the externality problem namely, a Pigovian subsidy to the leader, equal to the external benefit - does not always implement the social optimum in our setup. This is so because, when the externality is limited, the level of the subsidy is too low for the leader's payoff to exceed the followers' payoff, so that adoption delays persist.

By contrast, a patent holder can completely solve these two problems through inter-temporal price discrimination in the case where the IPR system is perfectly enforced. In particular, it has incentives to charge a lower price for the leader in order to trigger wider technology diffusion.

A last lesson concerns the enforcement of patent laws. It is widely acknowledged that in certain countries local authorities do not perfectly enforce patent laws. We show that imperfect enforcement always reduces social welfare. The competitive supply of technology might even be socially preferable to IP rights when imitation is easy. The reason is that discrimination can work in the wrong 
sense under imperfect enforcement: the price is higher for the leader, who needs to pay for the license to have the technology introduced in the country, than for the followers, who can imitate later on.

Our analysis has several limitations which can be addressed in future papers. In order to better isolate and characterize the strategic adoption patterns induced by learning spillovers, we have assumed that technology adoption was neutral with respect to competition. An obvious extension would thus consist in enriching the analysis by allowing the technology to affect the competitive position of the firms. We have shown that this would accelerate the diffusion of the technology, without necessarily doing away with the strategic delaying of adoption. Another interesting extension concerns the nature of spillovers. We have assumed in this paper that all firms follow the same learning curve starting from the date of the first adoption. The analysis could be enriched by allowing firms to follow different learning curves, and/or by assuming that spillovers affect production costs rather than fixed adoption costs.

\section{Appendix}

\subsection{Proof of Proposition 2}

The firm $i$ 's expected payoff at any time $t$ is given by the Bellman equation (6). Using this equation we derive successively the conditions for the different equilibriums to arise. 
10.1.1 No firm adopts $\left(x_{i} d t=0, \forall i=1, \ldots, n\right)$

Assume that $(n-1)$ firms do not adopt. Is $x_{i} d t=0$ the best reply of the last firm $i$ ? Its expected payoff can be written:

$$
P_{i}=v^{L} x_{i} d t+e^{-r d t} \prod_{k=1}^{n}\left(1-x_{k} d t\right) P_{i}
$$

Since we consider infinitesimal values of $d t$, we can eliminate all terms in $(d t)^{n}$, $n>1$. Noting moreover that $1-e^{-r d t} \sim r d t$ and $e^{-r d t} \rightarrow 1$, the expression can write:

$$
P_{i}=\frac{x_{i} v^{L}}{r+x_{i}}
$$

This expression is decreasing in $x_{i}$ if $v^{L}<0$. Hence the equilibrium where no firm adopts exists when $v^{L}<0$.

\subsubsection{One firm $j$ adopts immediately $\left(x_{j} d t=1\right)$}

In that case the expected payoff of the other firms $i \neq j$ is:

$$
P_{i}=v^{F}\left(d^{*}\right)+x_{i} d t\left[v^{L}-v^{F}\left(d^{*}\right)\right]
$$

If $v^{L}<v^{F}\left(d^{*}\right)$, the best reply for firm $i \neq j$ is clearly $x_{i} d t=0$. Knowing this we have to check whether firm $j$ will still play $x_{j} d t=1$. From (13) we know that firm $j$ 's payoff is $P_{j}=x_{j} v^{L} /\left(r+x_{j}\right)$ and that firm $j$ will play $x_{j} d t=1$ only if $v^{L}>0$. It follows that there are $n$ equilibrium in which one firm adopts immediately $\left(x_{j} d t=1\right)$ while the others do no adopt $\left(x_{i} d t=0, i \neq j\right)$ if $v^{F}\left(d^{*}\right)>v^{L}>0$.

If $v^{L}=v^{F}\left(d^{*}\right)$, firms $i \neq j$ can play any strategy $x_{i} \in[0,1]$. In that case 
the payoff of firm $j$ is:

$$
P_{j}=v^{L}+\prod_{k=1}^{n}\left(1-x_{k} d t\right)\left[e^{-r d t} P_{j}-v^{L}\right]
$$

As we consider infinitesimal values of $d t$, we can eliminate all terms in $(d t)^{n}$, $n>1$. Noting moreover that $1-e^{-r d t} \sim r d t$ and $e^{-r d t} \rightarrow 1$, the expression can write:

$$
P_{j}=\left(v^{L} \sum_{k=1}^{n} x_{k}\right)\left(r+\sum_{k=1}^{n} x_{k}\right)^{-1}
$$

$P_{j}$ is clearly increasing (respectively decreasing) in $x_{j}$ if $v^{L}>0$ (resp. $v^{L}<$ $0)$. Hence firm $j$ will play $x_{j} d t=1$ if $v^{L}>0$. It follows that there are $n$ equilibrium in which one firm adopts immediately $\left(x_{j} d t=1\right)$ while the others follow immediately $\left(x_{i} d t \in[0,1], i \neq j\right)$ if $v^{F}\left(d^{*}\right)=v^{L}>0$.

\subsubsection{All firms play mixed strategies}

Consider again the expected payoff of firm $i$ in (6). Using the previous approximations, we rewrite the expression:

$$
P_{i}=\left(x_{i} v^{L}+\sum_{k \neq i} x_{k} v^{F}\left(d^{*}\right)\right)\left(r+\sum_{k} x_{k}\right)^{-1}
$$

If $v^{F}\left(d^{*}\right)>v^{L} \geq 0$, the expected profit $P_{i}$ admits a maximum in $x_{i}$. The FOC of firm $i$ 's program yields:

$$
\sum_{k \neq i} x_{k}=\frac{r v^{L}}{v^{F}\left(d^{*}\right)-v^{L}}
$$


It is clear from (14) that only one equilibrium is possible, where $\hat{x}=\hat{x}$ for all $i=1, \ldots, n$. The equilibrium adoption strategy is then

$$
\hat{x}=\frac{r v^{L}}{[n-1]\left[v^{F}\left(d^{*}\right)-v^{L}\right]}
$$

The strategy $\hat{x}$ followed by each firm defines a Poisson process of parameter $n \hat{x}$ for the first adoption. This allows us to calculate the expected delay until the first adoption given by (8).

\subsection{Proof of Proposition 3}

We need to investigate precisely the impact of $s$ when it is exclusively granted to a unique firm. This is not so straightforward as it is not possible to replace $v^{L}$ by $v^{L}+s$ in the Bellman equation (6) for all firms as just one obtains the premium. As a result, the first adoption game does not solve according to Proposition 2.

A firm's willingness to accept the premium depends on the difference between its payoff if it adopts at $T=0$ and its payoff if not. In turn the payoff of refusing the premium depends on whether another firm accepts it.

Assume that another firm would accept the premium and adopt at $T=0$. Then the best reply of the other firms is to wait a delay $d^{*}$ before adopting in turn the technology, so that their payoff is $v^{F}\left(d^{*}\right)$. Knowing this, a firm will accept the premium if $v^{L}+s \geq v^{F}\left(d^{*}\right)$. This condition thus implies that one firm will accept the premium and adopt at time $T=0$ while the other will follow after a delay $d^{*}$.

If, on the other hand, we have $v^{L}+s<v^{F}\left(d^{*}\right)$, then being a follower (with $d^{*}>0$ ) is more profitable than accepting the premium. In this case the adoption game corresponds to the Bellman equation (6) in which $v^{L}$ is replaced with $v^{L}+z s$ where $z$ denotes the firm $i$ 's probability to obtain the premium when it decides to adopt the technology. Ruling out pure strategies, the likelihood 
that two firms or more adopt simultaneously is a term in $(d t)^{n}<1$, with $n>1$. For small time increments, this term becomes negligible $\left((d t)^{n} \sim 0, n>1\right)$ such that $z \sim 1$. As a result, Proposition 2, point 2c, can apply.

\subsection{Proof of Lemma 1}

Assume first that the followers have neither bought nor imitated the technology time $t \geq T+d^{f}$. Then, the best strategy for the monopolist is to sell the technology at the reservation price $f-\varepsilon$, where $\varepsilon$ is small and negligible, and to do so immediately at $t=T+d^{f}$ as its second-stage profit is $f e^{-r t}$. Recall that followers are price takers. They thus only decide when they purchase the technology. In this regard, they also want to do so at time $T+d^{f}$ as their profit $v^{F}(d)-f e^{-r d}$ is maximized when $d=d^{f}$.

Consider next the interval $\left[T, T+d^{f}\right)$. We know that a follower which could not purchase the technology imitates at $t=T+d^{f}$. Hence, it finds profitable to purchase the technology at time $T+d$ only if (11) holds, or equivalently if

$$
p^{F}(d) \leq e^{r d}\left[v^{F}(d)-v^{F}\left(d^{f}\right)\right]+f e^{-r\left(d^{f}-d\right)}
$$

This implies that the provider's profit is maximized with $p^{F}(d)=e^{r d}\left[v^{F}(d)-v^{F}\left(d^{f}\right)\right]+$ $f e^{-r\left(d^{f}-d\right)}$ if it sells the technology at date $T+d$ and it makes the second stage profit

$$
(n-1) e^{-r d} p^{F}(d)=(n-1)\left[v^{F}(d)-v^{F}\left(d^{f}\right)+f e^{-r\left(d^{f}\right)}\right]
$$

Moreover, the followers' profit is $v^{F}\left(d^{f}\right)-f e^{-r d^{f}}$.

Then, the delay $d$ which maximizes (15) is obviously $d^{*}$. It reaches this maximum by charging a price above $e^{r d}\left[v^{F}(d)-v^{F}\left(d^{f}\right)\right]+f e^{-r\left(d^{f}-d\right)}$ before $T+d^{*}$ to prevent adoption. Furthermore, the followers do not have any incentive to delay further adoption after $T+d^{*}$ as they anticipate that their profit will 
still be equal to $v^{F}\left(d^{f}\right)-f e^{-r d^{f}}$.

\subsection{Proof of Proposition 5}

The objective is to solve max $\Pi\left(p^{L}\right)$ subject to $\Pi\left(p^{L}\right) \geq 0$ and $v^{L}-p^{L} \geq 0$.

To do so, we need to study two cases: 1) $0 \leq v^{L}-p^{L} \leq v^{F}\left(d^{*}\right)-\hat{p}^{F} e^{-r d^{*}}$ in which a first firm adopts with a strictly positive expected delay $E(T)>0,2)$ $v^{L}-p^{L}>v^{F}\left(d^{*}\right)-\hat{p}^{F} e^{-r d^{*}}$ in which the firm adopts at $T=0$.

10.4.1 Case 1: $0 \leq v^{L}-p^{L} \leq v^{F}\left(d^{*}\right)-\hat{p}^{F} e^{-r d^{*}}$

The condition on $v^{L}-p^{L}$ is equivalent to $p^{L} \in I_{1} \equiv\left[v^{L}-v^{F}\left(d^{*}\right)+\hat{p}^{F} e^{-r d^{*}}, v^{L}\right]$ and the profit function is

$$
\begin{aligned}
\Pi\left(p^{L}\right) & =\int_{0}^{\infty} n \hat{y} e^{-n \hat{y} t}\left(p^{L}+(n-1) \hat{p}^{F} e^{-r d^{*}}\right) e^{-r t} d t \\
& =\frac{n\left(v^{L}-p^{L}\right)\left(p^{L}+(n-1) \hat{p}^{F} e^{-r d^{*}}\right)}{\left(v^{L}-p^{L}\right)+(n-1)\left(v^{F}\left(d^{*}\right)-\hat{p}^{F} e^{-r d^{*}}\right)}
\end{aligned}
$$

We differentiate (16) leading to

$$
\Pi^{\prime}\left(p^{L}\right)=\frac{n X\left(p_{L}\right)}{\left[\left(v^{L}-p^{L}\right)+(n-1)\left(v^{F}\left(d^{*}\right)-\hat{p}^{F} e^{-r d^{*}}\right)\right]^{2}}
$$

with

$d X / d p^{L}=\left(v^{L}-p^{L}\right)^{2}+(n-1)\left(v^{F}\left(d^{*}\right)-\hat{p}^{F} e^{-r d^{*}}\right)\left(v^{L}-2 p^{L}-(n-1) \hat{p}^{F} e^{-r d^{*}}\right)$

As $v^{F}\left(d^{*}\right)-\hat{p}^{F} e^{-r d^{*}}>0$, the denominator of $d \Pi / d p^{L}$ is strictly positive. We can therefore concentrate the analysis on $X$.

To begin with, $X$ is continuous and decreases with $p^{L}$ :

$$
d X / d p^{L}=-2\left(v^{L}-p^{L}\right)-2(n-1)\left(v^{F}\left(d^{*}\right)-\hat{p}^{F} e^{-r d^{*}}\right)<0 .
$$


This implies that the minimum of $X$ corresponds to the upper bound of $I_{1}$ :

$$
X_{\min } \equiv X\left(v^{L}\right)=-(n-1)\left(v^{F}\left(d^{*}\right)-\hat{p}^{F} e^{-r d^{*}}\right)\left(v^{L}+(n-1) \hat{p}^{F} e^{-r d^{*}}\right)
$$

which is positive if $v^{L}+(n-1) \hat{p}^{F} e^{-r d^{*}} \leq 0$ and negative otherwise as $v^{F}\left(d^{*}\right)-$ $\hat{p}^{F} e^{-r d^{*}}>0$

Conversely, the maximum is

$$
\begin{aligned}
X_{\max } & \equiv X\left(v^{L}-v^{F}\left(d^{*}\right)+\hat{p}^{F} e^{-r d^{*}}\right) \\
& =\left[v^{F}\left(d^{*}\right)-\hat{p}^{F} e^{-r d^{*}}\right]\left[(2 n-1) v^{F}\left(d^{*}\right)-n^{2} \hat{p}^{F} e^{-r d^{*}}-(n-1) v^{L}\right]
\end{aligned}
$$

The expression in the first bracket is positive, but the sign of the expression in the second bracket is ambiguous. For instance, it is negative when $n \rightarrow \infty$, but positive when $f$ is zero as $f=0$ implies $\hat{p}^{F}=0$ and as $v^{F}\left(d^{*}\right) \geq v^{L}$.

To sum up:

$$
\begin{aligned}
& X_{\min }>0 \text { if } v^{L}<-(n-1) \hat{p}^{F} e^{-r d^{*}} \\
& X_{\max }>0 \text { if } v^{L}<\frac{2 n-1}{n-1} v^{F}\left(d^{*}\right)-\frac{n^{2}}{n-1} \hat{p}^{F} e^{-r d^{*}}
\end{aligned}
$$

Moreover, simple calculations show that $-(n-1) \hat{p}^{F} e^{-r d^{*}}<\frac{2 n-1}{n-1} v^{F}\left(d^{*}\right)-$ $\frac{n^{2}}{n-1} \hat{p}^{F} e^{-r d^{*}}$. This leads us to consider three subcases : a) $v^{L} \geq \frac{2 n-1}{n-1} v^{F}\left(d^{*}\right)-$ $\frac{n^{2}}{n-1} \hat{p}^{F} e^{-r d^{*}}$, b) $-(n-1) \hat{p}^{F} e^{-r d^{*}} \leq v_{L}<\frac{2 n-1}{n-1} v^{F}\left(d^{*}\right)-\frac{n^{2}}{n-1} \hat{p}^{F} e^{-r d^{*}}$, c) $v^{L}<$ $-(n-1) \hat{p}^{F} e^{-r d^{*}}$

Subcase 1a: $v^{L} \geq \frac{2 n-1}{n-1} v^{F}\left(d^{*}\right)-\frac{n^{2}}{n-1} \hat{p}^{F} e^{-r d^{*}} \quad$ In this case, $X_{\max } \leq 0$. From $d X / d p^{L}<0$, it follows that $X$ is negative in the whole interval $I_{1}$. Hence, $\Pi$ is decreasing and the solution is given by the corner solution $\hat{p}^{L}=v^{L}-v^{F}\left(d^{*}\right)+$ $\hat{p}^{F} e^{-r d^{*}}$. This implies that $T=0$.

This is a possible equilibrium only if $\Pi\left(\hat{p}^{L}\right)=\hat{p}^{L}+(n-1) \hat{p}^{F} e^{-r d^{*}} \geq 0$. That 
is, if

$$
v^{L} \geq v^{F}\left(d^{*}\right)-n \hat{p}^{F} e^{-r d^{*}}
$$

We show that this condition is always satisfied by computing the difference:

$$
\begin{aligned}
\Delta & =\left(\frac{2 n-1}{n-1} v^{F}\left(d^{*}\right)-\frac{n^{2}}{n-1} \hat{p}^{F} e^{-r d^{*}}\right)-\left(v^{F}\left(d^{*}\right)-n \hat{p}^{F} e^{-r d^{*}}\right) \\
& =\frac{n}{n-1}\left(v^{F}\left(d^{*}\right)-\hat{p}^{F} e^{-r d^{*}}\right)>0
\end{aligned}
$$

which is positive. Hence, condition $v^{L} \geq \frac{2 n-1}{n-1} v^{F}\left(d^{*}\right)-\frac{n^{2}}{n-1} \hat{p}^{F} e^{-r d^{*}}$ is sufficient for (18) to hold.

Subcase 1b: $-(n-1) \hat{p}^{F} e^{-r d^{*}} \leq v_{L}<\frac{2 n-1}{n-1} v^{F}\left(d^{*}\right)-\frac{n^{2}}{n-1} \hat{p}^{F} e^{-r d^{*}} \quad$ In this case, $X_{\max }>0$ and $X_{\min }<0$. As $X$ is monotonic, there exists an interior maximum $\hat{p}^{L} \in I_{1}$ which is defined by $X\left(\hat{p}^{L}\right)=0$. It remains to check whether $\Pi\left(\hat{p}^{L}\right) \geq 0$.

As $v^{L} \neq \hat{p}^{L}$, we can manipulate $X\left(\hat{p}^{L}\right)=0$ to get:

$\left(v^{L}-\hat{p}^{L}\right)+(n-1)\left(v^{F}\left(d^{*}\right)-\hat{p}^{F} e^{-r d^{*}}\right)=\frac{(n-1)\left(v^{F}\left(d^{*}\right)-\hat{p}^{F} e^{-r d^{*}}\right)\left(\hat{p}^{L}+(n-1) \hat{p}^{F} e^{-r d^{*}}\right)}{v^{L}-\hat{p}^{L}}$.

Then, plugging this expression in (16) and simplifying, we get

$$
\Pi\left(p^{L}\right)=\frac{n\left(v^{L}-\hat{p}^{L}\right)^{2}}{(n-1)\left(v^{F}\left(d^{*}\right)-\hat{p}^{F} e^{-r d^{*}}\right)}
$$

which is positive.

Subcase 1c: $v^{L}<-(n-1) \hat{p}^{F} e^{-r d^{*}} \quad$ In this case, $X_{\min }>0$. As $d X / d p^{L}<0$, $X$ is thus positive in $I_{1}$. As a result, the maximum corresponds to the upper bound of $I_{1}: \hat{p}^{L}=v^{L}$, which is not a feasible solution as (16) implies $\Pi\left(p^{L}\right)=$ $v^{L}+(n-1) \hat{p}^{F} e^{-r d^{*}}<0$. 
10.4.2 Case 2: $v^{L}-p^{L} \geq v^{F}\left(d^{*}\right)-\hat{p}^{F} e^{-r d^{*}} \Longleftrightarrow p^{L} \leq v^{L}-v^{F}\left(d^{*}\right)+\hat{p}^{F} e^{-r d^{*}}$ This case is simple as the leader adopts at $T=0$, so that $\Pi\left(p^{L}\right)=p^{L}+(n-$ 1) $\hat{p}^{F} e^{-r d^{*}}$. П obvioulsy increases with $p_{L}$. As a result we get the corner solution $\hat{p}^{L}=v^{L}-v^{F}\left(d^{*}\right)+\hat{p}^{F} e^{-r d^{*}}$. We have already seen in subcase 1a that this price yields a positive profit only if (18) holds. The difference with subcase 1a is that (18) is not systematically satisfied anymore.

\subsubsection{Conclusion}

In summary,

- The technology provider does not sell the technology when $v_{L} \leq-(n-$ 1) $\hat{p}^{F} e^{-r d^{*}}$.

- If $v^{L} \in\left(-(n-1) \hat{p}^{F} e^{-r d^{*}}, v^{F}\left(d^{*}\right)-n \hat{p}^{F} e^{-r d^{*}}\right]$, the interior solution defined by $X\left(p_{L}\right)=0$ yields a strictly positive profit. In this case, adoption occurs with a strictly positive delay $E(T)>0$.

- If $v^{L} \in\left[v^{F}\left(d^{*}\right)-n \hat{p}^{F} e^{-r d^{*}}, \frac{2 n-1}{n-1} v^{F}\left(d^{*}\right)-\frac{n^{2}}{n-1} \hat{p}^{F} e^{-r d^{*}}\right]$, we get the interior solution in Case 1 and the corner solution in Case 2. However, the continuity of $\Pi$ implies that the interior solution dominates the corner solution.

- If $v^{L} \geq \frac{2 n-1}{n-1} v^{F}\left(d^{*}\right)-\frac{n^{2}}{n-1} \hat{p}^{F} e^{-r d^{*}}$, the equilibrium price is $\hat{p}^{L}=v^{L}-$ $v^{F}\left(d^{*}\right)+\hat{p}^{F} e^{-r d^{*}}$ with $T=0$.

\section{References}

[1] Bolton, P. and J. Farell (1990) "Decentralization, duplication, and delay", Journal of Political Economy, 98, pp 803-926. 
[2] Cabral, L. and C. Dezso (2008) "Technology Adoption with Multiple Alternative Designs and the Option to Wait", Journal of Economics and Management Strategy, 17, pp 413-441.

[3] Choi, J.P. (1994) "Irreversible Choice of Uncertain Technologies with Network Externalities" RAND Journal of Economics, 25, 382-401.

[4] David, P. and T. Olsen (1992) "Technology Adoption, Learning Spillovers, and the Optimal Duration of Patent-based Monopolies," International Journal of Industrial Organization, 10, pp 517-543.

[5] Erutku, C., and Y. Richelle (2007), "Optimal Licensing Contracts and the Value of a Patent", Journal of Economics and Management Strategy, 16(2), 407-436.

[6] Fudenberg, D. and J. Tirole (1985) "Preemption and Rent Equalization in the Diffusion of New Technology" Review of Economic Studies, 52, 383-401.

[7] Fudenberg, D. and J. Tirole (1991) Game Theory, The MIT Press: Cambridge.

[8] Glass, J. (2004) "Outsourcing under Imperfect Protection of Intellectual Property" Review of International Economics, 12(5), 867-884.

[9] Glass, J. and K. Saggi (2002) "Intellectual Property Rights and Foreign Direct Investment" Journal of International Economics, 56, 387-410.

[10] Gruber H. (1998) "Learning by Doing and Spillovers: Further Evidence from the Semiconductor Industry", Review of Industrial Organization, 13(6), 697-711.

[11] Hoppe (2002) "The Timing of New Technology Adoption: Theoretical Models and Empirical Evidence" The Manchester School, 70(1), pp 56-76. 
[12] Irwin D. A. and P.J. Klenow (1994) "Learning-by-Doing Spillovers in the Semiconductor Industry", Journal of Political Economy, 102(6), 1200-27.

[13] Kamien, M. (1992) "Patent Licensing", in R. Aumann and S. Hart, eds, Handbook of Game Theory, vol. I, Amstredam, North-Holland.

[14] Katz, M.L. and C. Shapiro (1987) "R\&D Rivalry with Licensing or Imitation", American Economic Review, 77, pp 402-420.

[15] Katz, M.L. and C. Shapiro (1987) "Technology Adoption in the Presence of Network Externalities", Journal of Political Economy, 94, pp 822-841.

[16] Kristiansen, E.G. (2006) "R\&D and Buyers' Waiting Option", Journal of Industrial Economics, 54, pp 31-42.

[17] Lai, E. (1998) "International Intellectual Property Rights Protection and the Rate of Innovation" Journal of Development Economics, 55, 133-153.

[18] Lai, E. and L. Qiu (2003) "The North's Intellectual Property Rights Standards for the South?" Journal of International Economics, 59, 183-209.

[19] Mariotti, M. (1992) "Unused Innovations" Economic Letters, 38, 367-371.

[20] Maskus, K. E. (2000) Intellectual Property Rights in the Global Economy. Institute for International Economics, Washington D.C.

[21] Reinganum, J. (1981) "Market Structure and the Diffusion of New Technology" Bell Journal of Economics, 12, 618-624.

[22] Smith, P. J. (2001) "How do foreign patent rights affect U.S. exports, affiliate sales, and licenses?" Journal of International Economics, 55, 411-439.

[23] Thornton R.A. and P. Thompson (2001) "Learning from Experience and Learning from Others: An Exploration of Learning and Spillovers in Wartime Shipbuilding, American Economic Review, 91(5), 1350-1368 